\title{
Internet of things enabled real time water quality monitoring system
}

\author{
S. Geetha* (1) and S. Gouthami
}

\author{
* Correspondence: \\ geethaciteee@gmail.com \\ Department of Electrical and \\ Electronics Engineering, Coimbatore \\ Institute of Technology, Coimbatore \\ 641014, India
}

\begin{abstract}
Smart solutions for water quality monitoring are gaining importance with advancement in communication technology. This paper presents a detailed overview of recent works carried out in the field of smart water quality monitoring. Also, a power efficient, simpler solution for in-pipe water quality monitoring based on Internet of Things technology is presented. The model developed is used for testing water samples and the data uploaded over the Internet are analyzed. The system also provides an alert to a remote user, when there is a deviation of water quality parameters from the pre-defined set of standard values.
\end{abstract}

Keywords: Water quality, Smart solution, Internet of things, Wi-Fi, Cloud storage

\section{Background}

Ensuring the safety of water is a challenge due the excessive sources of pollutants, most of which are man-made. The main causes for water quality problems are overexploitation of natural resources. The rapid pace of industrialization and greater emphasis on agricultural growth combined with latest advancements, agricultural fertilizers and non-enforcement of laws have led to water pollution to a large extent. The problem is sometimes aggravated due to the non-uniform distribution of rainfall. Individual practices also play an important role in determining the quality of water (Central Ground Water Board, 2017).

Water quality is affected by both point and non-point sources of pollution, which include sewage discharge, discharge from industries, run-off from agricultural fields and urban run-off. Other sources of water contamination include floods and droughts and due to lack of awareness and education among users. The need for user involvement in maintaining water quality and looking at other aspects like hygiene, environment sanitation, storage and disposal are critical elements to maintain the quality of water resources.

Poor water quality spreads disease, causes death and hampers socio-economic progress. Around 5 million people die due to waterborne diseases around the world (Water Resource Information System of India, 2017). Fertilizers and pesticides used by farmers can be washed through the soil by rain, to end up in rivers. Industrial waste products are also washed into rivers and lakes. Such contaminations enter the food chain and accumulate until they reach toxic levels, eventually killing birds, fish and mammals. Chemical factories also dispose wastes in the water. Factories use water from rivers to power machinery or to cool down machinery. Raising the temperature

(c) The Author(s). 2017 Open Access This article is distributed under the terms of the Creative Commons Attribution 4.0 International License (http://creativecommons.org/licenses/by/4.0/), which permits unrestricted use, distribution, and reproduction in any medium, provided you give appropriate credit to the original author(s) and the source, provide a link to the Creative Commons license, and indicate if changes were made. 
of the water lowers the level of dissolved oxygen and upsets the balance of life in the water (Central Ground Water Board, 2017). All the above factors make water quality monitoring essential.

Water quality monitoring is defined as the collection of information at set locations and at regular intervals in order to provide data which may be used to define current conditions, establish trends, etc. (Niel et al., 2016; Muinul et al., 2014; Jianhua et al., 2015). Main objectives of online water quality monitoring include measurement of critical water quality parameters such as microbial, physical and chemical properties, to identify deviations in parameters and provide early warning identification of hazards. Also, the monitoring system provides real time analysis of data collected and suggest suitable remedial measures.

The aim of this paper is twofold. One is to provide a detailed survey of recent work carried out in the area of smart water quality monitoring in terms of application, communication technology used, types of sensors employed etc. Second, is to present a low cost, less complex smart water quality monitoring system using a controller with inbuilt Wi-Fi module to monitor parameters such as $\mathrm{pH}$, turbidity and conductivity. The system also includes an alert facility, to inform the user on deviation of water quality parameters.

\section{Related work}

Figure 1 shows the general building blocks of smart online monitoring solutions considered in this section.

Three main subsystems identified include

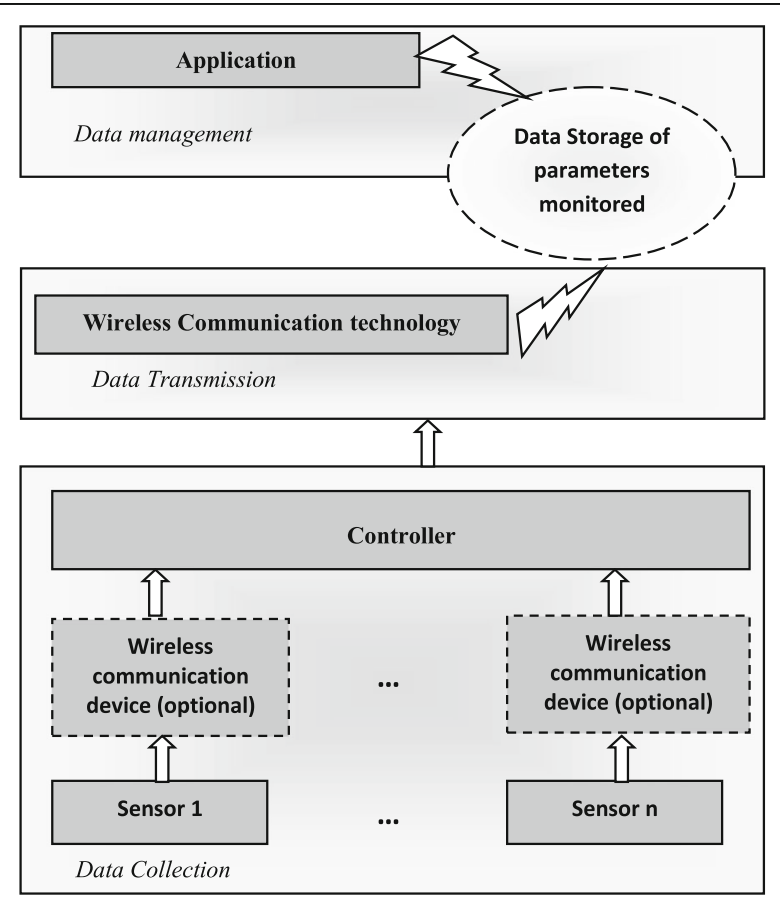

Fig. 1 Block diagram of Smart water Quality monitoring 
- Data management subsystem includes the application which accesses the data storage cloud and displays the same to the end user.

- Data transmission subsystem consists of a wireless communication device along with build in security features, which transmits the data from the controller to data storage cloud.

- Data collection subsystem consists of multi-parameter sensors and optional wireless communication device to transmit the sensor information to the controller. A controller gathers the data, processes the same.

Sensors form the bottom most part of the block diagram. Several sensors are available to monitor water quality parameters. These sensors are placed in the water to be tested which can be either stored water or running water. Sensors convert the physical parameter into equivalent measurable electrical quantity, which is given as input to controllers through an optional wireless communication device. Main function of the controller is to read the data from the sensor, optionally process it, and send the same to the application by using appropriate communication technology. Choice of the communication technology and the parameters to be monitored depends on the need of the application. Application includes the data management functions, data analysis and alert system based on the monitored parameters. This section further discusses the previous work carried out in each of the subsystems.

\section{Application}

Online smart water quality has been proposed for several applications in literature as shown in Table 1.

Domestic water is intended for human consumption for drinking and cooking purposes. The Bureau of Indian Standards (Central Ground Water Board, 2017) provides details about acceptable limits of substances such as Aluminium, Ammonia, Iron, Zinc etc. Traditional water quality measurement involves manual collection of water at

Table 1 Applications of smart water quality monitoring

\begin{tabular}{ll}
\hline Application & References \\
\hline Domestic running water & Vijayakumar and Ramya (2015), Niel et al. (2016), \\
& Theofanis et al. (2014), Jayti and Jignesh (2016), \\
& Poonam et al., 2016, Xin et al. (2011), \\
& Xiuli et al. (2011), Offiong et al. (2014) \\
& Thinagaran et al. (2015), Vinod and \\
Domestic Stored water & Sushama (2016), Pandian and \\
& Mala (2015), Azedine et al. (2000), \\
& Sathish et al. (2016) \\
& Tomoaki et al. (2016), Vinod and \\
Lake, River, Sea water, Environmental monitoring & Sushama (2016), Peng et al. (2009), \\
& Francesco et al. (2015), Christie et al. (2014), \\
& Haroon and Anthony (2016), \\
& Anthony et al. (2014), Li et al. (2013) \\
Aquaculture centers & Goib et al. (2015), Xiuna et al. (2010), \\
Drinking water distribution systems & Gerson et al. (2012) \\
Water and Air quality & Eliades et al. (2014), Ruan and Tang (2011) \\
Not limited to specific application & Mitar et al. (2016) \\
\hline
\end{tabular}


various locations, storing the samples in centralized location and subjecting the samples to laboratory analytical testing (Thinagaran et al., 2015; Vinod \& Sushama, 2016; Pandian \& Mala, 2015; Azedine et al., 2000; Offiong et al., 2014). Such approaches are not considered efficient due to the unavailability of real time water quality information, delayed detection of contaminants and not cost effective solution. Hence, the need for continuous online water quality monitoring in highlighted in (Vijayakumar \& Ramya, 2015; Niel et al., 2016; Theofanis et al., 2014; Bhatt \& Patoliya, 2016; Poonam et al., 2016; Xin et al., 2011; Xiuli et al., 2011; Sathish et al., 2016).

Smart water quality approaches have been considered for lake and sea water applications. For such applications, distributed wireless sensor networks are required to monitor the parameters over a larger area and send the data monitored to a centralized controller using wireless communication. Such applications normally monitor parameters such as chlorophyll (Francesco et al., 2015), dissolved oxygen concentration (Christie et al., 2014; Anthony et al., 2014) and temperature (Peng et al., 2009; Francesco et al., 2015; Christie et al., 2014).

Aquaculture centers require water quality monitoring and forecasting for healthy growth of aquatic creatures (Goib et al., 2015; Gerson et al., 2012; Xiuna et al., 2010). In (Gerson et al., 2012) authors have developed biosensors using Arduino microcontroller to monitor animal behavioral changes due to aquatic pollution. The abnormal behavior of animals can be considered as an indication of water contamination. In (Xiuna et al., 2010) authors have proposed a smart water quality monitoring system to forecast water quality using artificial neural networks. Extensive tests have been carried out for a period of 22 months at isolated local area network and the data has been transferred to internet using CDMA technology.

Water quality monitoring in distribution systems is challenging in the context of management of distributed wireless sensor networks (WSN). A water distribution network for monitoring chlorine concentration has been presented in (Eliades et al., 2014). Solar enabled distributed WSN has been proposed in (Ruan \& Tang, 2011) for monitoring parameters such as $\mathrm{pH}$, turbidity and oxygen density. Water at different sites is monitored in real-time using an architecture composed of solar cell enabled sensor nodes and base station. Flexibility, low carbon emission and low power consumption are the advantages of the method proposed in the paper. A combined system for water and air quality measurement is proposed in (Mitar et al., 2016) using additional sensors for measuring air temperature and relative humidity.

\section{Parameters monitored}

Based on extensive experimental evaluation carried out by US Environmental Protection Agency (USEPA) it has been concluded that chemical and biological contaminants used have an effect on many water parameters monitored including Turbidity (TU), Oxidation Reduction Potential (ORP), Electrical Conductivity (EC) and pH. Thus, by monitoring and detecting changes in the water parameters, it is feasible to infer the water quality (Theofanis et al., 2014).

A detailed list of work carried out to monitor water parameters is presented in Table 2. The $\mathrm{pH}$ of the water is one of the most important factors when investigating water quality, as it measures how basic or acidic the water is. Water with a $\mathrm{pH}$ of 11 or higher can 
Table 2 Parameters monitored

\begin{tabular}{|c|c|}
\hline Parameters monitored & References \\
\hline $\mathrm{pH}$ & $\begin{array}{l}\text { Vijayakumar and Ramya (2015), Mitar et al. (2016), Tomoaki et al. (2016), Vinod and } \\
\text { Sushama (2016), Niel et al. (2016), Goib et al. (2015), Theofanis et al. (2014), Peng et al. } \\
\text { (2009), Jayti and Jignesh (2016), Poonam et al., 2016, Xin Wang (2011), Gerson et al. } \\
\text { (2012), Pandian and Mala (2015), Liang (2014), Xiuna et al. (2010), Christie et al. (2014), } \\
\text { Azedine et al. (2000), Offiong et al. (2014), Anthony et al. (2014), Sathish et al. (2016) }\end{array}$ \\
\hline Dissolved Oxygen & $\begin{array}{l}\text { Vijayakumar and Ramya (2015), Goib et al. (2015), Jayti and Jignesh (2016), Gerson et } \\
\text { al. (2012), Liang (2014), Xiuna et al. (2010), Christie et al. (2014), Offiong et al. (2014), } \\
\text { Anthony et al. (2014) }\end{array}$ \\
\hline $\begin{array}{l}\text { Oxidation reduction } \\
\text { potential }\end{array}$ & Niel et al. (2016), Theofanis et al. (2014) \\
\hline Temperature & $\begin{array}{l}\text { Vijayakumar and Ramya (2015), Mitar et al. (2016), Niel et al. (2016), Theofanis et al. } \\
\text { (2014), Peng et al. (2009), Jayti and Jignesh (2016), Poonam et al., 2016, Gerson et al. } \\
\text { (2012), Pandian and Mala (2015), Liang (2014), Xiuna et al. (2010), Francesco et al. } \\
\text { (2015), Christie et al. (2014), Azedine et al. (2000), Anthony et al. (2014) }\end{array}$ \\
\hline Turbidity & $\begin{array}{l}\text { Vijayakumar and Ramya (2015), Tomoaki et al. (2016), Vinod and Sushama (2016), } \\
\text { Theofanis et al. (2014), Jayti and Jignesh (2016), Poonam et al., 2016, Gerson et al. } \\
\text { (2012), Pandian and Mala (2015), Francesco et al. (2015), Offiong et al. (2014), Sathish } \\
\text { et al. (2016) }\end{array}$ \\
\hline Conductivity & $\begin{array}{l}\text { Vijayakumar and Ramya (2015), Niel et al. (2016), Theofanis et al. (2014), Jayti and } \\
\text { Jignesh (2016), Gerson et al. (2012), Francesco et al. (2015), Christie et al. (2014), } \\
\text { Azedine et al. (2000), Anthony et al. (2014), Sathish et al. (2016) }\end{array}$ \\
\hline Water level sensing & Thinagaran et al. (2015) \\
\hline Flow sensing & Niel et al. (2016) \\
\hline Air temperature & Mitar et al. (2016) \\
\hline Relative Humidity & Mitar et al. (2016) \\
\hline $\begin{array}{l}\text { Presence of organic } \\
\text { compounds }\end{array}$ & Mitar et al. (2016) \\
\hline Chlorine concentration & Eliades et al. (2014), Francesco et al. (2015) \\
\hline Chlorophyll & Francesco et al. (2015) \\
\hline
\end{tabular}

cause irritation to the eyes, skin and mucous membrane. Acidic water ( $\mathrm{pH} 4$ and below) can also cause irritation due to its corrosive effect (Niel et al., 2016). Measurement of dissolved oxygen (DO) is important for aquaculture centers since this parameter determines whether or not a species can survive in the said water source. ORP is a measure of degree to which a substance is capable of oxidizing or reducing another substance. ORP is measured in milli volts (mv) using an ORP meter. Tap water and bottled water have a positive value of ORP. Turbidity refers to concentration of suspended particles in water. Conductivity gives an indication of the amount of impurities in the water, the cleaner the water, the less conductive it is. In many cases, conductivity is also directly associated with the total dissolved solids (TDS).

\section{Communication technology used}

Wireless technology is used for communication between sensor to controller and from controller to data storage cloud as shown in Fig. 1. Different technology has been used in each of the communication scenario. Table 3 shows the frequently used wireless communication technology for information transfer.

\section{Communication between sensors and controller}

Sensors are connected to the controller, either directly using UART protocol or remotely using Zigbee protocol. ZigBee is a technology of data transfer in wireless 
Table 3 Wireless communication technology used

\begin{tabular}{|c|c|c|}
\hline Communication & Technology used & References \\
\hline \multirow[t]{2}{*}{$\begin{array}{l}\text { Between sensors } \\
\text { and controller }\end{array}$} & Zigbee & $\begin{array}{l}\text { Vinod and Sushama (2016), Niel et al. (2016), Theofanis } \\
\text { et al. (2014), Peng et al. (2009), Jayti and Jignesh } \\
\text { (2016), Poonam et al., 2016, Xin et al. (2011), } \\
\text { Pandian and Mala (2015), Liang (2014), Christie } \\
\text { et al. (2014), Offiong et al. (2014), Anthony et al. } \\
\text { (2014), Li et al. (2013) }\end{array}$ \\
\hline & UART & $\begin{array}{l}\text { Tomoaki et al. (2016), Wei et al. (2012), Vijayakumar } \\
\text { and Ramya (2015), Thinagaran et al. (2015), Mitar } \\
\text { et al. (2016), Sathish et al. (2016) }\end{array}$ \\
\hline \multirow[t]{5}{*}{$\begin{array}{l}\text { Between controller } \\
\text { and application }\end{array}$} & GSM/GPRS & $\begin{array}{l}\text { Peng et al. (2009), Xin et al. (2011), Liang (2014), } \\
\text { Wei et al. (2012), Francesco et al. (2015), Anthony } \\
\text { et al. (2014), Tomoaki et al. (2016) }\end{array}$ \\
\hline & Ethernet LAN & Theofanis et al. (2014) \\
\hline & IoT (using external WiFi Module) & $\begin{array}{l}\text { Vijayakumar and Ramya (2015), Thinagaran et al. } \\
\text { (2015), Mitar et al. (2016), Jayti and Jignesh (2016), } \\
\text { Poonam et al., 2016, Sathish et al. (2016) }\end{array}$ \\
\hline & IoT (using inbuilt WiFi Module) & Proposed \\
\hline & LCD, Alarm, Actuators. & $\begin{array}{l}\text { Vinod and Sushama (2016), Niel et al. (2016), } \\
\text { Li et al. (2013) }\end{array}$ \\
\hline
\end{tabular}

network. It has a low energy consumption and is designed for multichannel control systems, alarm system and lighting control. ZigBee builds on the physical layer and media access control defined in IEEE standard 802.15.4 for low-rate WPANs. In smart water quality systems, Zigbee protocol is used for communication between sensor nodes and the controller when the sensors are placed in remote location away from the controller. For in-pipe domestic monitoring, direct connection of sensors and controller is preferred.

In (Tomoaki et al., 2016) authors have developed a WSN system for water quality monitoring. Sensors are connected to the transmission module using UART. Communication with the outside of the sensor nodes is performed with the Internet connection using the 3G mobile network. Authors in (Theofanis et al., 2014) have proposed a water quality monitoring system for in-pipe monitoring and assessment of water quality on fly. Sensor nodes are installed in the pipes that supply water at consumer sites.

\section{Communication between controller and data storage}

Communication between controller and centralized data storage is carried out using long range communication standards such as $3 G$ and Internet. Some the previous works aim at alerting the user in form of SMS about the water quality. Such systems (Peng et al., 2009; Xin et al., 2011; Liang, 2014; Wei et al., 2012) require additional SIM card for the GPRS module connected with the controller. The drawbacks of such systems are additional cost for SIM card operation. Also, large quantities of data storage and retrieval are not possible at the user premises. Recently, IoT enabled solutions are gaining importance. Authors in (Alessio et al., 2016) provide a survey on the wide range of applications possible with Internet of Things and Cloud computing.

IoT is a recent communication paradigm in which objects of everyday day life are equipped with microcontrollers, transceivers for digital communication, which will make the objects communicate with one another and the users, thus becoming an integral part of the Internet (Bushra \& Mubashir, 2016; Biljana et al., 2017; Andrea et al., 2014). In (Vijayakumar \& Ramya, 2015; Thinagaran et al., 2015; Mitar et al., 2016) an external Wi-Fi 
module is connected to the controller, which enables the controller to get connected to the nearest Wi-Fi hotspot and subsequently to the Internet cloud.

\section{Controller used}

Different controllers have been used in literature for smart water quality monitoring as listed in Table 4. Though each controller have its own salient features, most of the controllers used in literature work with external GPRS / Wi-Fi module for connectivity to the data storage or application.

The proposed model in this paper uses TI CC3200, a controller with built in Wi-Fi module and dedicated ARM MCU for wireless communication purpose. TI CC3200 reduces the complexity and improves speed of operation compared with controllers with external Wi-Fi module (Texas instrument CC3200 Simple Link, 2017). A comparison of various microcontrollers and embedded boards used in the literature for smart water quality monitoring are provided in Table 7.

\section{Sensors used}

Several sensors are commercially available for water quality monitoring. Such sensors are used in (Thinagaran et al., 2015; Vinod \& Sushama, 2016; Niel et al., 2016). Some of the works published in literature include fabricated sensors for improved usability. A fabricated buoy type sensor node is used for parameter monitoring in (Tomoaki et al., 2016). The fabricated sensor includes a solar cell, Li-ion battery, a power module and transmission module. A in-house fabricated $\mathrm{TiO}_{2}$ based thick film $\mathrm{pH}$ resistive sensor is used in (Mitar et al., 2016). This sensor module output can be directly connected to the microcontroller without additional signal processing electronics. In (Theofanis et al., 2014), authors have developed low cost, easy to use and accurate turbidity sensor for continuous in-pipe turbidity monitoring. In (Francesco et al., 2015), authors have presented a sea water probe for monitoring multiple parameters intended for sea water quality monitoring Table 5.

Extensive data analysis and information processing has been presented in (Theofanis et al., 2014; Peng et al., 2009; Xiuna et al., 2010; Francesco et al., 2015; Azedine et al., 2000). A hierarchical routing algorithm to reduce the communication overhead and increase the life time of WSN suitable for river/lake water monitoring has been presented in (Haroon \& Anthony, 2016).

In (Public Utilities Board Singapore (PUB), 2016), a review on Smart Water Grid system with integration of communication technologies (ICT) is provided. An integrated

Table 4 Controller Used

\begin{tabular}{ll}
\hline Controller used & References \\
\hline AtMega & Thinagaran et al. (2015), Mitar et al. (2016) \\
PIC & Theofanis et al. (2014), Niel et al. (2016), Vinod and Sushama (2016) \\
Raspberry pi + IOT & Vijayakumar and Ramya (2015), Jayti and Jignesh (2016), Sathish et al. (2016) \\
ARM LPC & Francesco et al. (2015), Poonam et al. (2016) \\
Arduino & Anthony et al. (2014), Christie et al. (2014), Pandian and Mala (2015), Gerson et al. (2012) \\
8051 & Li et al. (2013) \\
MSP430 & Peng et al. (2009) \\
TI CC3200 & Proposed work \\
\hline
\end{tabular}


Table 5 Sensors used for water quality monitoring

\begin{tabular}{|c|c|c|}
\hline Sensors used & References & Remarks \\
\hline $\begin{array}{l}\text { Fabricated buoy type } \\
\text { sensor node. }\end{array}$ & Tomoaki et al. (2016) & $\begin{array}{l}\text { Solar enabled sensor node with power } \\
\text { module and transmission module }\end{array}$ \\
\hline Solar cell enabled sensors & \multicolumn{2}{|l|}{ Ruan and Tang (2011) } \\
\hline $\begin{array}{l}\text { Fabricated TiO2-based thick } \\
\text { film pH resistive sensor }\end{array}$ & Mitar et al. (2016) & $\begin{array}{l}\text { Designed to ensure reliable measurements } \\
\text { without any additional signal processing }\end{array}$ \\
\hline Fabricated Turbidity sensor & Theofanis et al. (2014) & $\begin{array}{l}\text { Designed to be compatible with WSN } \\
\text { technology, in-pipe placement, low } \\
\text { cost and accuracy }\end{array}$ \\
\hline $\begin{array}{l}\text { ISO/IEC/IEEE 21451-2 } \\
\text { compliant sea water } \\
\text { probe }\end{array}$ & Francesco et al. (2015) & $\begin{array}{l}\text { Single Probe capable of measuring water } \\
\text { temperature, salinity/ } \\
\text { conductivity, turbidity and chlorophyll }\end{array}$ \\
\hline $\begin{array}{l}\text { Standard commercially } \\
\text { available sensors }\end{array}$ & \multicolumn{2}{|c|}{$\begin{array}{l}\text { Vijayakumar and Ramya (2015), Thinagaran et al. (2015), Vinod } \\
\text { and Sushama (2016), Niel et al. (2016), Theofanis et al. (2014), Eliades } \\
\text { et al. (2014), Peng et al. (2009), Jayti and Jignesh (2016), Poonam } \\
\text { et al. (2016), Xin et al. (2011), Gerson et al. (2012), Pandian and Mala } \\
\text { (2015), Liang (2014), Wei et al. (2012), Xiuna et al. (2010), Francesco } \\
\text { et al. (2015), Christie et al. (2014), Offiong et al. (2014), Anthony et al. } \\
\text { (2014), Sathish et al. (2016), Li et al. (2013) }\end{array}$} \\
\hline
\end{tabular}

management model covering the entire water cycle from sources to tap for securing the stability, safety and efficiency of water has been discussed in (Woon et al., 2016).

\section{Power consumption related issues}

Power consumption is a major constraint for IoT applications, because the applications are most likely to operate on batteries. Communication of data is a major source of power consumption. For applications such as smart water quality monitoring, data communication occurs in two stages. One is the communication between sensors and the controller and other is the communication between controller and application. Table 6 shows several possible short distance communication protocols applicable (Al-Fuqaha et al., 2015; Ray, 2016). Possible protocols for communication between sensor nodes and controller are Zigbee, Blue tooth, BLE and LoRa. Wi-Fi is not suitable for communication between sensor nodes and the controller because the power dissipation is high (Shuker et al., 2016). As per our literature survey, all the works have used zigbee protocol for communication between sensor nodes and controller.

Table 6 Short distance communication protocols

\begin{tabular}{|c|c|c|c|c|}
\hline \multirow[t]{2}{*}{ Parameter } & \multicolumn{4}{|c|}{ Short distance protocols } \\
\hline & ZigBee & Bluetooth & LoRa & $\mathrm{Wi}-\mathrm{Fi}$ \\
\hline Standard & IEEE 802.15.4 & $\begin{array}{l}\text { IEEE } \\
802.15 .1\end{array}$ & LoRaWAN R1.0 & IEEE $802.11 \mathrm{a} / \mathrm{c} / \mathrm{b} / \mathrm{d} / \mathrm{g} / \mathrm{n}$ \\
\hline Transmission range & $10-20 \mathrm{~m}$ & $8-10 \mathrm{~m}$ & $<30 \mathrm{Km}$ & 20-100 m \\
\hline $\begin{array}{l}\text { Energy } \\
\text { consumption }\end{array}$ & Low & $\begin{array}{l}\text { Bluetooth: } \\
\text { Medium } \\
\text { BLE: Very } \\
\text { Low }\end{array}$ & Very low & High \\
\hline Data Rate & $40-250 \mathrm{~Kb} / \mathrm{s}$ & $1-24 \mathrm{Mb} / \mathrm{s}$ & $0.3-50 \mathrm{~Kb} / \mathrm{s}$ & $1 \mathrm{Mb} / \mathrm{s}-6.75 \mathrm{~Gb} / \mathrm{s}$ \\
\hline Cost & Low & Low & High & High \\
\hline Usage & \multicolumn{3}{|c|}{$\begin{array}{l}\text { Communication between } \\
\text { sensor and controller }\end{array}$} & $\begin{array}{l}\text { Communication between } \\
\text { controller and application }\end{array}$ \\
\hline
\end{tabular}


The proposed work is aimed at domestic water quality monitoring. The sensors are assumed to be connected in-pipe. The controller and the sensors form a single module installed in the user premises. Therefore, the sensors are directly connected to controller. For applications such as lake, river and sea water monitoring, sensors and the controller are separated by considerable distance. Under such conditions, short range communication protocols (such as Zigbee), listed in Table 6 are used.

For communication between controller and the application, Wi-Fi is a compelling choice. With other short range protocols, the sensor nodes communicate with controller easily, but when trying to connect the system to the Internet some type of adapter that is able to communicate with both the sensors and the Internet is needed. This is additional hardware overhead. With Wi-Fi, the above problem does not arise, because there is an infrastructure that is already built and is in existence. The limitation of WiFi is that, the standard was designed for laptops and PCs, where power requirement is completely different from battery operated smart objects. Hence, manufacturers have started developing low-power Wi-Fi devices. Power management and extended battery life are primary focus areas for embedded low-power Wi-Fi devices such as CC3200. In order to reduce power consumption, the microcontroller is operated in one of the four power modes, namely Hibernate, Low Power Deep Sleep mode, Sleep mode and Active mode (Texas instrument CC3200 Simple Link, 2017).

In (Thomas et al., 2016) authors have compared the power consumption of standalone microcontroller with Zigbee, Bluetooth Low Energy (BLE) modules and controller with inbuilt Wi-Fi device. From the experimental results, it has been found that Wi-Fi inbuilt device consumes less power compared to standalone microcontrollers. The reason is due to extra power consumption while establishing and deestablishing connection during transmission in standalone devices. In Wi-Fi inbuilt controller, the Wi-Fi module goes into sleep mode, while retaining the previous connections made. Therefore, each time the Wi-Fi module awakens, a new connection need not be established. This reduces the power consumption to a large extent. Table 7 shows a comparison of CC3200 with the microcontroller and embedded boards used in literature (Al-Fuqaha et al., 2015; Ray, 2016).

\section{Proposed system}

\section{Hardware design}

The key parameters monitored in the proposed system are conductivity, turbidity, water level and $\mathrm{pH}$. The block diagram of the proposed system is shown in Fig. 2.

A controller forms the central part of the IoT enabled water quality monitoring system. As seen from Table 4, it is observed that most of the IoT based solutions use a controller with external Wi-Fi. Such designs are not cost effective, power efficient and also result in complex circuitry. In this work, TI CC3200 is a single chip microcontroller with in-built Wi-Fi module and ARM Cortex M4 core, which can be connected to the nearest Wi-Fi hot spot for internet connectivity.

Sensors are directly interfaced to the controller since the proposed system is to monitor domestic water quality. The sensor parameters such as conductivity, turbidity, water level and $\mathrm{pH}$ are measured by placing the sensor into different solutions of water. The measured parameters can be viewed by using LCD. The data from the sensors are sent to the cloud using the controller. Threshold is set in the cloud based on the standards 


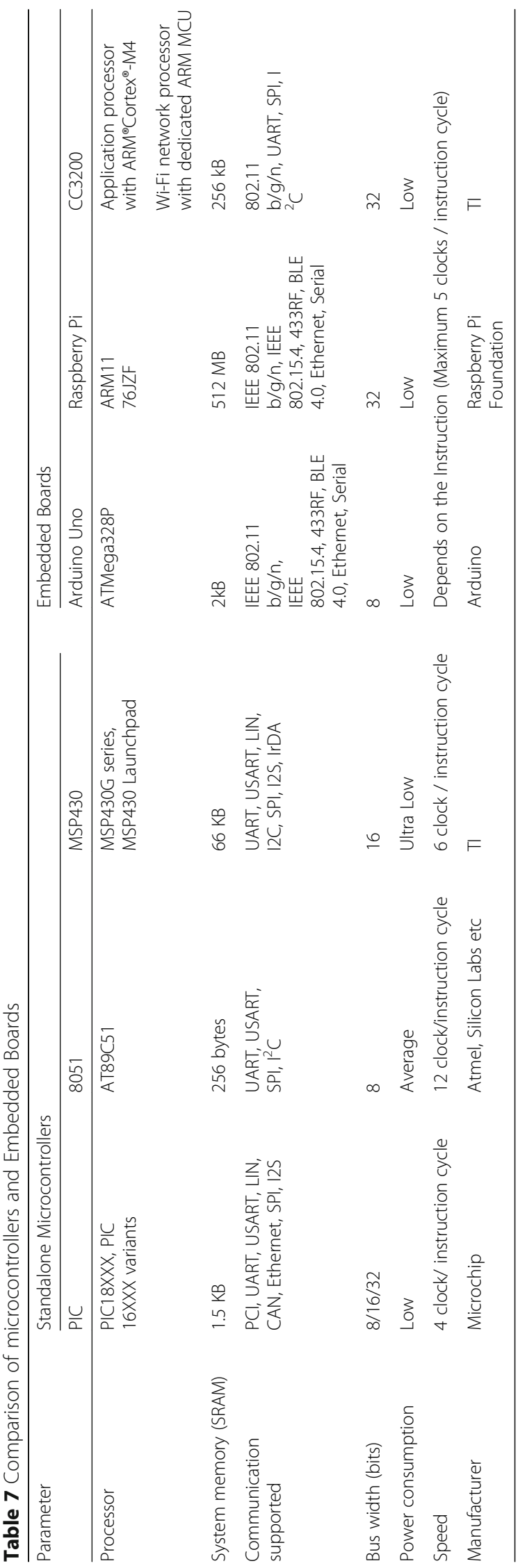




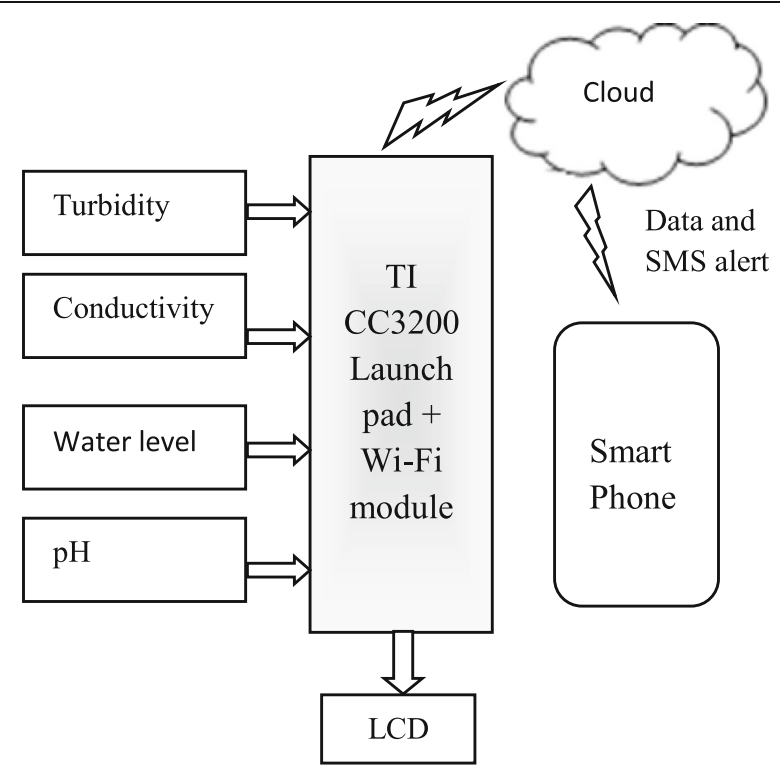

Fig. 2 Block diagram of the proposed system

provided by WHO. Message is sent from cloud to the users mobile if the value exceeds the threshold. A mobile application has been developed in which values obtained by each sensor in the cloud can be viewed. This can be used by both the water quality monitoring authorities as well as users. A detailed circuit diagram of the proposed system is shown in Fig. 3.

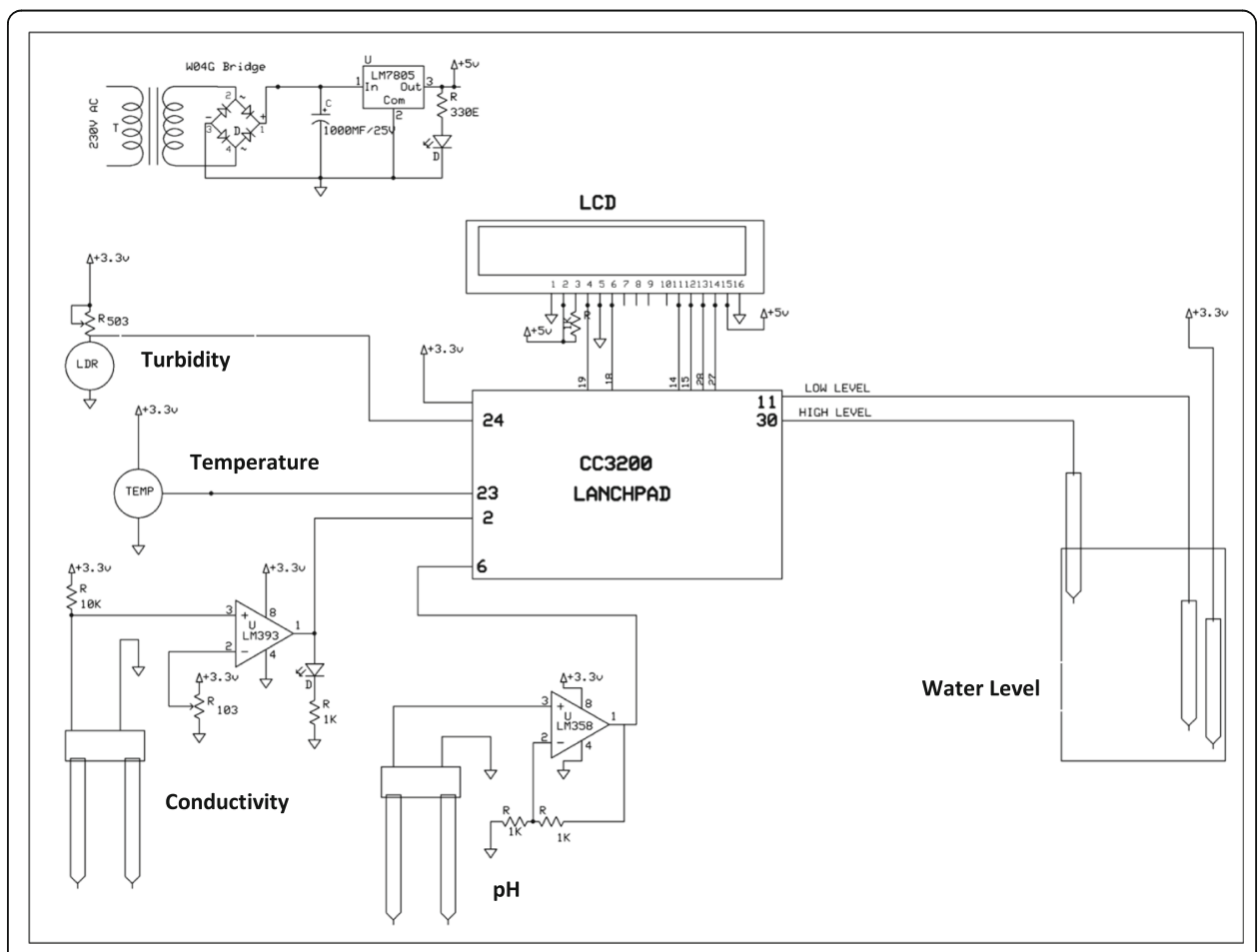

Fig. 3 Circuit diagram of the proposed system 


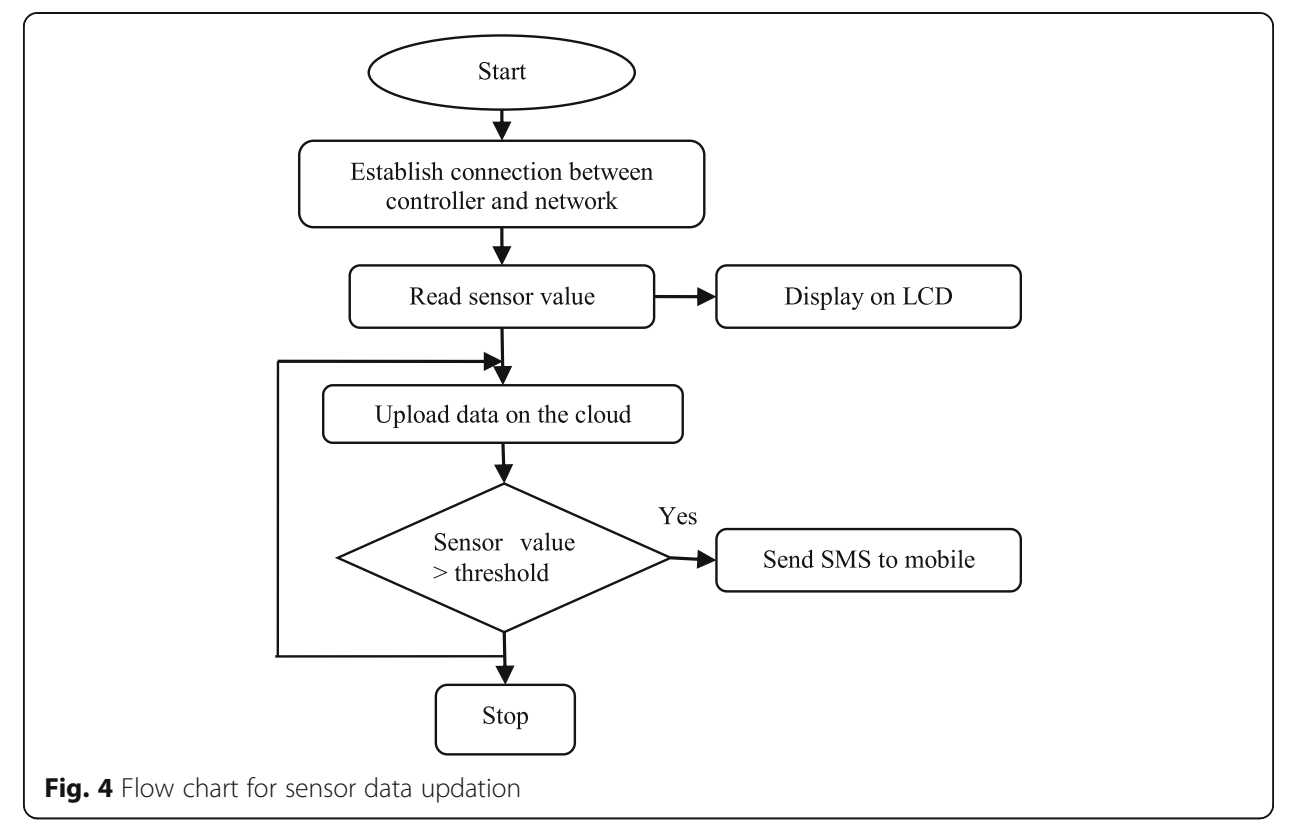

Table 8 Summary of useful features of Ubidots cloud platform

\begin{tabular}{|c|c|c|c|}
\hline Features & Description & Options available & \\
\hline \multirow[t]{18}{*}{ Dashboard } & \multirow{18}{*}{$\begin{array}{l}\text { Create real-time dashboards to } \\
\text { analyze data or control devices. }\end{array}$} & \multirow[t]{5}{*}{ Chart } & Line chart \\
\hline & & & Double Axis \\
\hline & & & Scatter plot \\
\hline & & & Histogram \\
\hline & & & Bars \\
\hline & & \multirow[t]{6}{*}{ Metric } & Average \\
\hline & & & Maximum \\
\hline & & & Minimum \\
\hline & & & Sum \\
\hline & & & Count \\
\hline & & & Last value \\
\hline & & Map & Location of device \\
\hline & & \multirow[t]{2}{*}{ Table } & Last value \\
\hline & & & Historical \\
\hline & & \multirow[t]{2}{*}{ Indicator } & Gauge \\
\hline & & & On/off display \\
\hline & & \multirow[t]{2}{*}{ Control } & Switch \\
\hline & & & Slider \\
\hline Devices & $\begin{array}{l}\text { Ubidots supports more than } 50 \text { devices to } \\
\text { be connected with an option to enable LoRa. }\end{array}$ & & \\
\hline \multirow[t]{6}{*}{ Events } & \multirow{6}{*}{$\begin{array}{l}\text { Create SMS, Email, Telegram or Webhook } \\
\text { alerts based on your sensor data. }\end{array}$} & \multicolumn{2}{|l|}{ Send Email } \\
\hline & & \multicolumn{2}{|l|}{ Send SMS } \\
\hline & & \multicolumn{2}{|l|}{ Send Telegram } \\
\hline & & \multicolumn{2}{|l|}{ Web Hook } \\
\hline & & \multicolumn{2}{|l|}{ Set a variable } \\
\hline & & \multicolumn{2}{|l|}{ Trigger Events } \\
\hline
\end{tabular}


Table 9 Safe limits for drinking water as per WHO standards

\begin{tabular}{lll}
\hline Parameters monitored & Quality range & Units \\
\hline Turbidity & $5-10$ & $\mathrm{NTU}$ \\
$\mathrm{pH}$ & $6.5-8.5$ & $\mathrm{pH}$ \\
Conductivity & $300-800$ & $\mathrm{microS} / \mathrm{cm}$ \\
\hline
\end{tabular}

Conductivity is the measure of solutions ability to carry current. This parameter is used to determine the salt content in the water. In the proposed design, YL-69 is used to measure the conductivity of the water. It consists of two electrodes, when placed in water a potential is generated which is proportional to conductivity. It is measured in seimens per $\mathrm{cm}$. Acceptable range of conductivity is from 300 to $800 \mu$ seimens per $\mathrm{cm}$.

$\mathrm{pH}$ measures amount of acid or base in the solution. Three in 1 ph meter with inverting operating amplifier is used to measure $\mathrm{pH}$. Inverting Op-amp is used to boost the voltage from $\mathrm{mV}$ to voltage range. $\mathrm{pH}$ sensor consists of two electrodes which is reference electrode and $\mathrm{pH}$ electrode also known as measuring electrode. When placed in the solution $\mathrm{pH}$ electrode develops a potential that is proportional to $\mathrm{pH}$. The value ranges from 0 to 14 . The acceptable range of $\mathrm{pH}$ for drinking water is 6.5 to 8.5 .

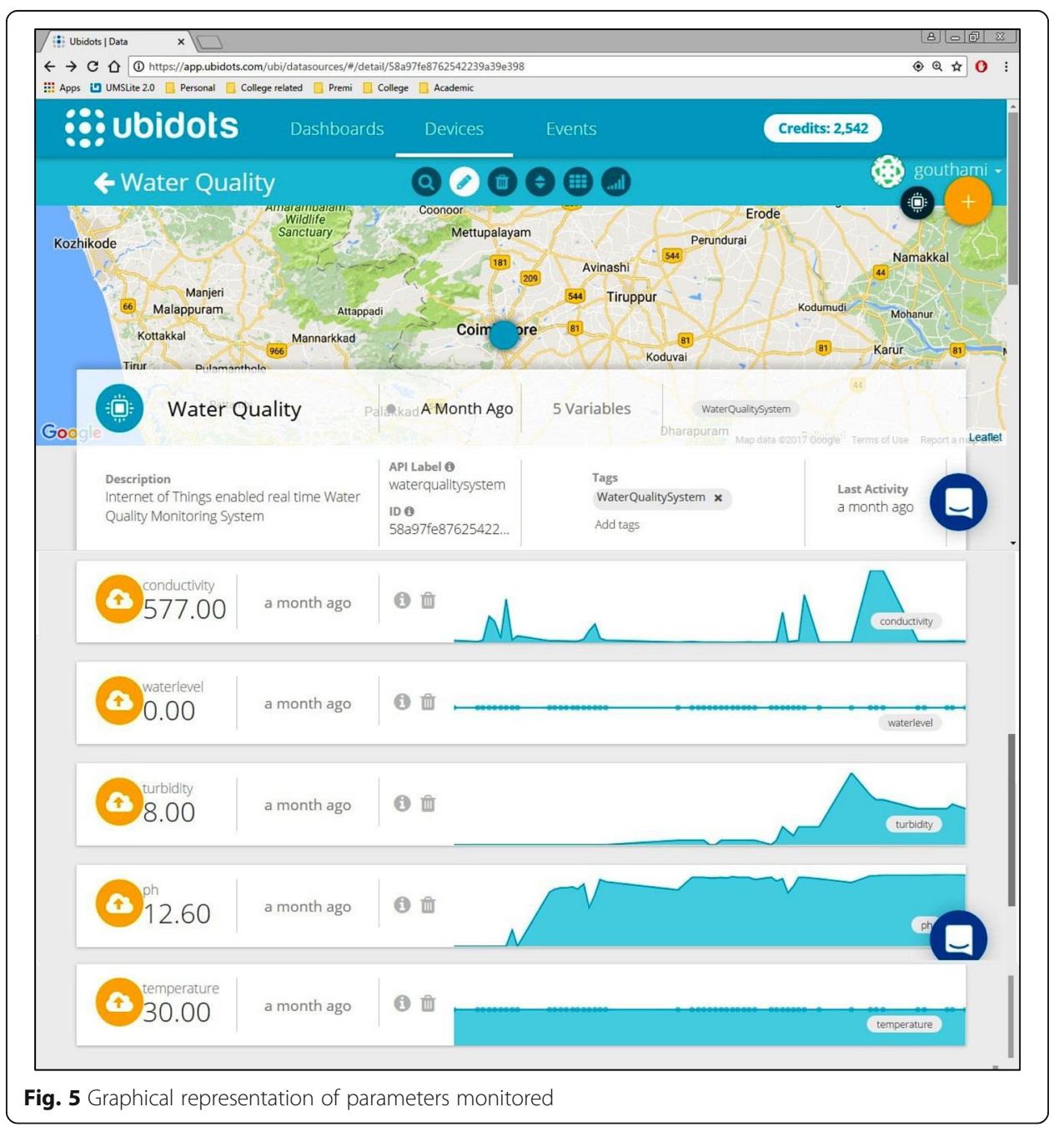


Table 10 Parameters measured with different water samples

\begin{tabular}{llll}
\hline Parameters & Drinking water (filter) & \multicolumn{2}{l}{ Pipe water } \\
\cline { 3 - 4 } & & Sample 1 & Sample 2 \\
\hline ph & 6.5 & 7.9 & 8.4 \\
conductivity & 448 & 577 & 580 \\
turbidity & 4 & 5 & 5 \\
\hline
\end{tabular}

Turbidity is a measure of cloudiness in the water. Opto electronic devices such as LDR and LED are used to measure the turbidity. Light is transmitted and reflected by suspended solids and reflected light is received by the sensors. An LDR is high resistance semiconductor. If light falling on the device is of high frequency, photons absorbed by the semiconductor gives the bound electrons enough energy to jump into the conduction band. In the proposed system distance between the LED and LDR is $9 \mathrm{~cm}$. The resulting free electrons conduct electricity thereby lowering resistance.

Water level is sensed to determine the depth of the water in the tank. This is done using probe method. Three probes are used to indicate the level of the water such as high, low and medium.

\section{Software design}

The flow chart for sensor data updation in the cloud is shown in Fig. 4. Reading from the sensor is constantly updated in the cloud and also displayed in the LCD connected. The programming is done using ENERGIA IDE.

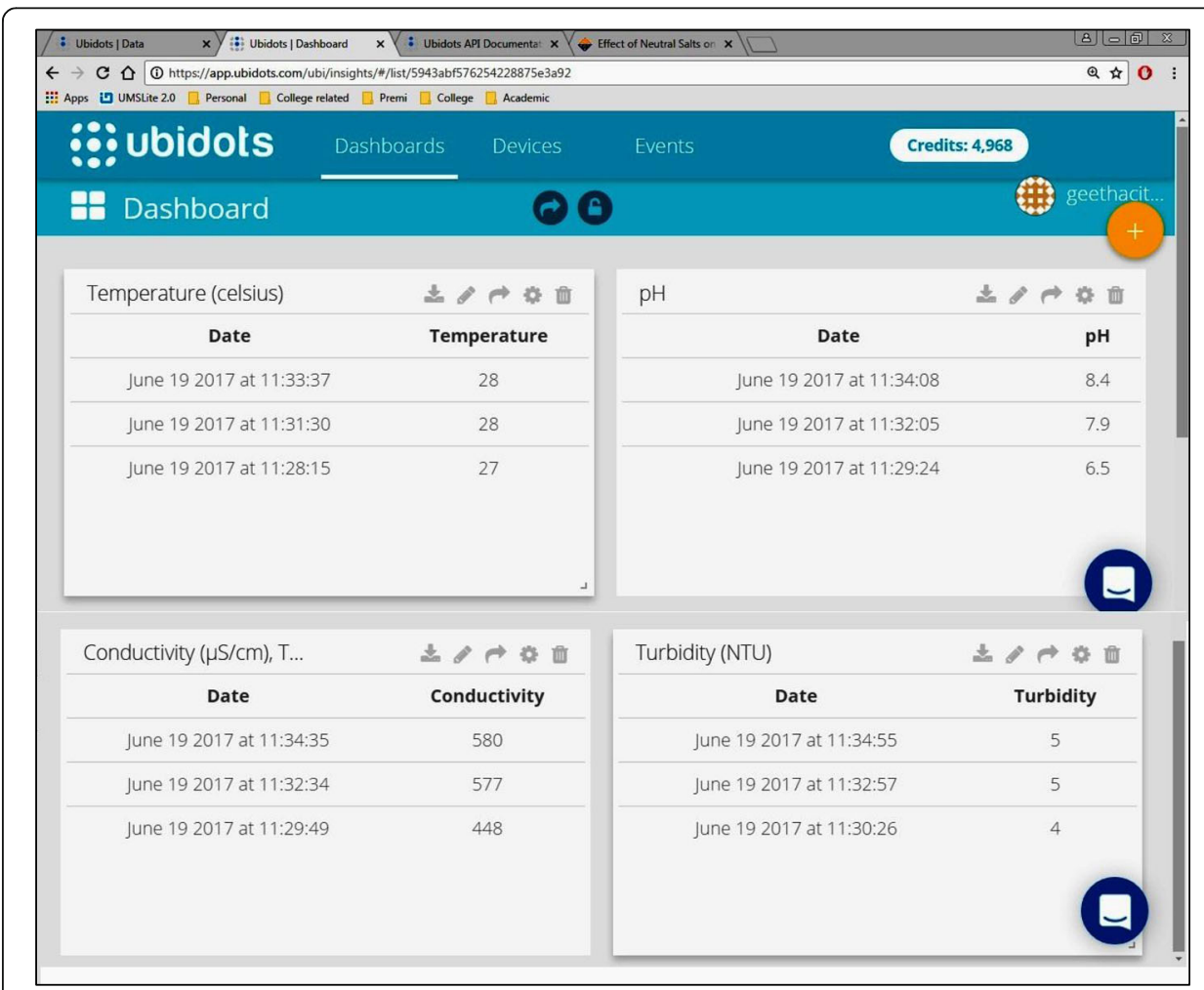

Fig. 6 Values stored in the Ubidots cloud 
Table 11 Results of the parameters monitored by adding contaminants (soil)

\begin{tabular}{llll}
\hline Amount of contaminants in $\mathrm{mg}$ & $\mathrm{ph}$ & (Conductivity) $(\mu \mathrm{S} / \mathrm{cm})$ & (Turbidity) (NTU) \\
\hline 5 & 6.7 & 570 & 8 \\
10 & 6.9 & 571 & 10 \\
15 & 6.7 & 581 & 15 \\
20 & 6.8 & 616 & 17 \\
25 & 6.9 & 787 & 18 \\
30 & 6.8 & 807 & 25 \\
35 & 6.7 & 993 & 29 \\
\hline
\end{tabular}

Data sent from the controller are stored in "Ubidots" cloud. "Ubidots" offers a platform for developers to capture data and turn it into useful information. The features include a real-time dashboard to analyze data or control devices and share the data through public links. Data stored in the cloud can be used for detailed analysis. The cloud is programmed to send alert SMS messages whenever the monitored parameter exceeds the threshold limit. The Table 8 presents a summary of useful features of Ubidots cloud platform (Ubidots, 2017).

The system is connected to the Ubidots cloud using the following steps:

1. Connect to the access point using ssid and password through mobile phone or personal computer.

2. The controller is then connected to the access point using Wi-Fi.

3. Login to cloud platform, where a token is generated

4. Use the token id in the program.

5. Data from the controller are loaded into the cloud.

6. Data can be viewed on the cloud platform.

\section{Results and Discussion}

Five parameters namely conductivity, $\mathrm{pH}$, turbidity, temperature and water level are measured using the experimental setup. The setup is connected to the Ubidots platform. The measured results are compared with drinking water quality standards defined by WHO. Table 9 lists the safe limit for the parameters considered in this work.

Figure 5 shows the graphical representation of parameters monitored and stored in the cloud over a period of time. Further, experiments were conducted by placing the

Table 12 Results of the parameters monitored by adding contaminants (salt)

\begin{tabular}{llll}
\hline Amount of contaminants in $\mathrm{mg}$ & $\mathrm{ph}$ & Conductivity) $(\mu \mathrm{S} / \mathrm{cm})$ & (Turbidity) NTU) \\
\hline 5 & 7.9 & 428 & 5 \\
10 & 8.1 & 358 & 6 \\
15 & 8.0 & 448 & 5 \\
20 & 7.9 & 590 & 7 \\
25 & 8.0 & 787 & 7 \\
30 & 8.3 & 895 & 8 \\
35 & 8.2 & 998 & 8 \\
\hline
\end{tabular}




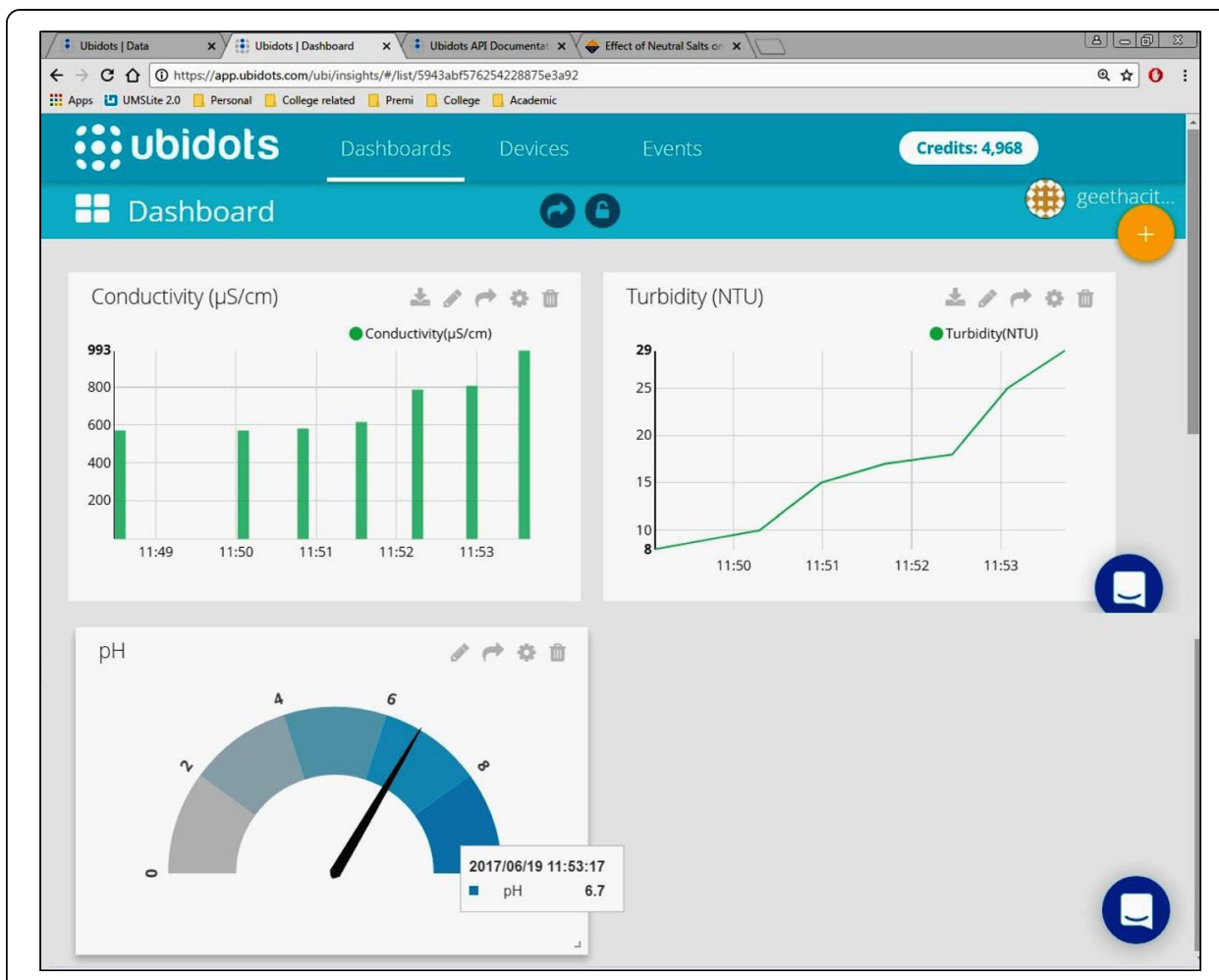

Fig. 7 Usage of Widgets for parameter monitoring

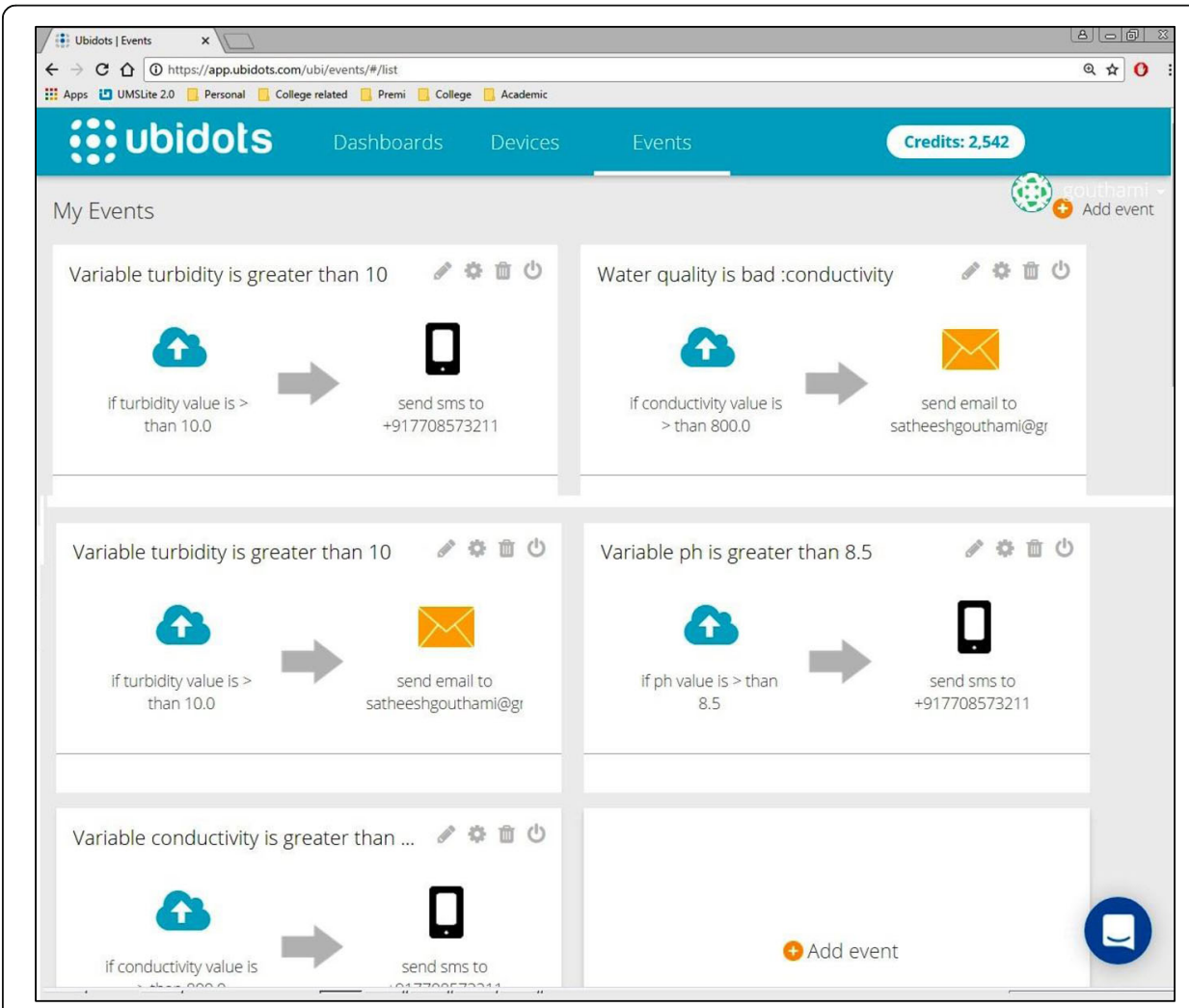

Fig. 8 Events created for alert 
sensors in the different solutions of water collected in the college premises. Table 10 shows the value of parameters measured for three different samples.

Figure 6 shows the above results as seen from the Ubidots platform. Further, to demonstrate the working of the system, and the various options for data analysis, measured quantity of contaminants such as salt and soil are mixed with $350 \mathrm{ml}$ of pipe water and testing is performed. The test results are tabulated in Tables 11 and 12 respectively.

Figure 7 shows the dashboard with widgets to view the results of data collected in the cloud for results in Table 11.

The other feature is creation of events, based on measured parameter values. The events stored can be programmed to automatically send SMS, email and other forms of alerts to the user whenever any parameter exceeds the threshold limit. Figure 8 shows a sample of events created for different parameters under consideration in this work Fig. 9 shows the alert SMS send to the mobile due to increased value of turbidity and conductivity.

\section{Conclusion and future work}

The paper presents a detailed survey on the tools and techniques employed in existing smart water quality monitoring systems. Also, a low cost, less complex water quality monitoring system is proposed. The implementation enables sensor to provide online

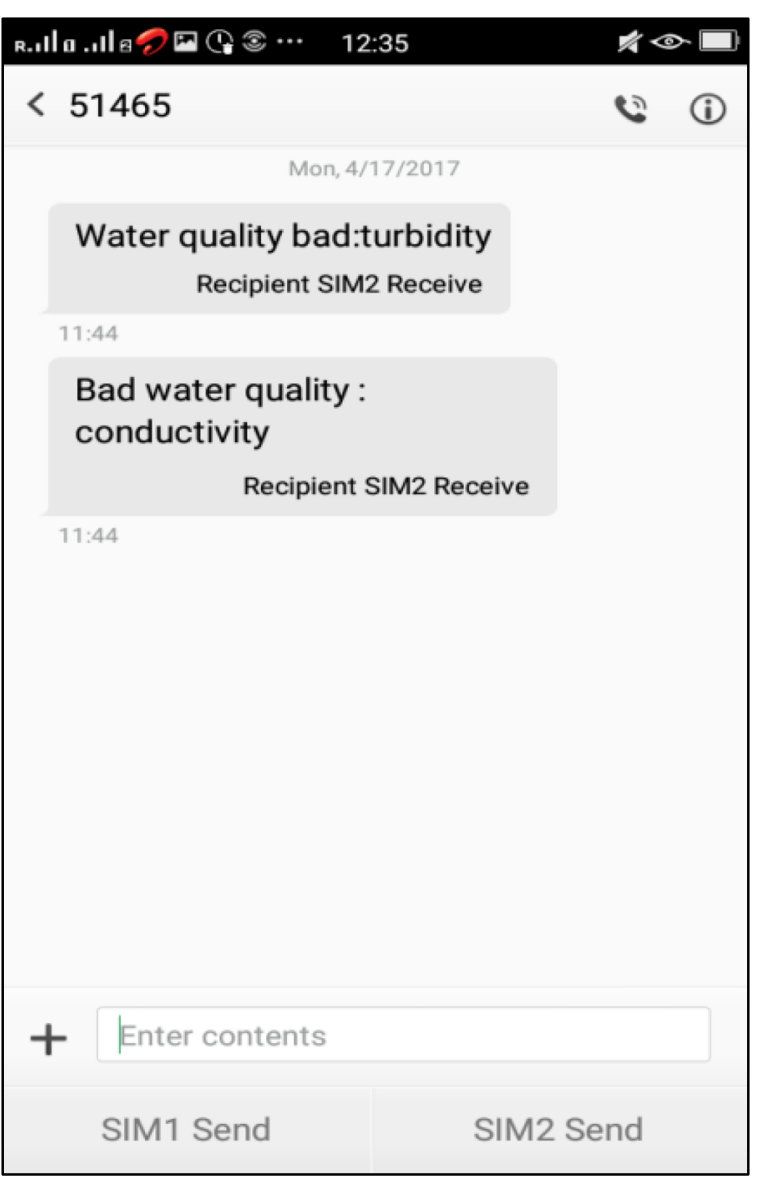

Fig. 9 Message sent from cloud to smart phone 
data to consumers. The experimental setup can be improved by incorporating algorithms for anomaly detections in water quality.

\begin{abstract}
Abbreviations
ARM: Advanced RISC Machine; BLE: Bluetooth Low Energy; CDMA: Code Division Multiple Access; DO: Dissolved Oxygen; EC: Electrical Conductivity; GPRS: General Packet Radio Service; GSM: Global System For Mobile Communications; ICT: Information and Communication Technologies; IDE: Integrated Development Environment; IOT: Internet Of Things; LAN: Local Area Network; LCD: Liquid Crystal Display; LDR: Light Dependent Resistor; LED: Light Emitting Diode; MCU: Micro Controller Unit; ORP: Oxidation Reduction Potential; SIM: Subscriber Identity Module; SMS: Short Message Service; TDS: Total Dissolved Solids; TU: Turbidity; UART: Universal Asynchronous Receiver/ Transmitter; USEPA: US Environmental Protection Agency; WHO: World Health Organization; WPAN: Wireless Personal Area Network; WSN: Wireless Sensor Network
\end{abstract}

\title{
Acknowledgements
}

Not applicable.

\section{Funding}

Not applicable.

\section{Availability of data and materials}

Not applicable.

\section{Authors' contributions}

Geetha carried out the literature survey, supervised the work, analyzed the data, drafted the manuscript and is responsible for submission. Gouthami developed the hardware module, collected the data and contributed in drafting the manuscript. Final manuscript has been read and approved by both the authors.

\section{Ethics approval and consent to participate}

Not Applicable.

\section{Consent for publication}

Not Applicable.

\section{Competing interests}

The authors declare that they have no competing interests

\section{Publisher's Note}

Springer Nature remains neutral with regard to jurisdictional claims in published maps and institutional affiliations.

Received: 2 May 2017 Accepted: 20 July 2017

Published online: 27 July 2017

\section{References}

Alessio B, Walter D, Valerio P, Antonio P (2016) Integration of Cloud computing and Internet of Things: A survey. Futur Gener Comput Syst 56:684-700

Al-Fuqaha A et al (2015) Internet of Things: A Survey on Enabling Technologies, Protocols, and Applications. IEEE Commun Surv Tutorials 17(4):2347-2376

Andrea Z, Nicola B, Angelo C, Lorenzo V, Michele Z (2014) Internet of Things for Smart Cities. IEEE Internet Things J 1(1):22-32 Anthony F, Aloys N, Hector J, Maria C, Albino J, Samuel B (2014) Wireless Sensor Networks for Water Quality Monitoring and Control within Lake Victoria Basin: Prototype Development. Wirel Sens Netw 6:281-290

Azedine C, Antoine G, Patrick B, Michel M (2000) Water quality monitoring using a smart sensing system. Measurement:219-224

Bhatt Jayti, Jignesh Patoliya (2016), "IoT based water quality monitoring system", In: Proc of 49th IRF Int Conf, 21 Feb 2016

Biljana L, Risteska S, Kire VT (2017) A review of Internet of Things for smart home: Challenges and solutions. J Clean Prod 140(3):1454-1464

Bushra R, Mubashir HR (2016) Applications of wireless sensor networks for urban areas: A survey. J Netw Comput Appl 60:192-219

Central Ground Water Board (2017) Ministry of Water Resources, River Development and Ganga Rejuvenation, Government of India. http://cgwb.gov.in/. Accessed 24 July 2017

Christie R, Mallory C, Jared L, Alan M (2014) Remote Delay Tolerant Water Quality Monitoring. In: IEEE global humanitarian technology conference, 10-13 Oct 2014

Eliades D, Lambrou T, Panayiotou C, Polycarpou M (2014) Contamination Event Detection in Water Distribution Systems using a Model-Based Approach. In: 16th Conference on Water Distribution System Analysis. 14-17 July 2014

Francesco A, Filippo A, Carlo GC, Anna ML (2015) A Smart Sensor Network for Sea Water Quality Monitoring. IEEE Sensors J 15(5):2514-2522

Gerson G, Christopher B, Stephen M, Richard O (2012) Real-time Detection of Water Pollution using Biosensors and Live Animal Behavior Models, In: 6th eResearch Australasia Conference, 28 Oct -1 Nov 2012

Goib W, Yudi Y, Dewa P, Iqbal S, Dadin M (2015) Integrated online water quality monitoring. In: International conference on smart sensors and application, 26-28 May 2015

Haroon M, Anthony S (2016) Towards Monitoring the Water Quality Using Hierarchal Routing Protocol for Wireless Sensor Networks. In: 7th International Conference on Emerging Ubiquitous Systems and Pervasive Networks, 19-22 Sep, 2016 
Jianhua D, Guoyin W, Huyong Y, Ji X, Xuerui Z (2015) A survey of smart water quality monitoring system. Environ Sci Pollut Res 22(7):4893-4906

Li Z, Wang K, Liu B (2013) Sensor-Network based Intelligent Water Quality Monitoring and Control. Int J Adv Res Comput Engg Tech 2(4):1659-1662

Liang Li (2014) Software development for water quality's monitoring centre of wireless sensor network. Computer Modeling New Tech 132-136

Mitar S, Goran M, Libu M, Krzystof Z (2016) Multi-sensor system for remote environmental (air and water) quality monitoring. In: 24th telecommunications forum, 22-23 Nov. 2016

Muinul H, Syed I, Alex F, Homayoun N, Rehan S, Manuel R, Mina H (2014) Online Drinking Water Quality Monitoring: Review on Available and Emerging Technologies. Crit Rev Env Sci Tech 44(12):1370-1421

Niel AC, Reza M, Lakshmi N (2016) Design of Smart Sensors for Real-Time Water Quality Monitoring. J IEEE Access 4: 3975-3990

Offiong N, Abdullahi S, Chile B, Raji H, Nweze N (2014) Real Time Monitoring Of Urban Water Systems for Developing Countries. IOSR J Comput Eng 16(3):11-14

Pandian DR, Mala K (2015) Smart Device to monitor water quality to avoid pollution in loT environment. Int J Emerging Tech Comput Sci Electron 12(2):120-125

Peng J, Hongbo X, Zhiye H, Zheming W (2009) Design of a Water Environment Monitoring System Based on Wireless Sensor Networks. J Sensors 9:6411-6434

Poonam J, Chavan, Manoj AM (2016) IoT Based Water Quality Monitoring. Int J Modern Trends Eng Res 3(4):746-750

Public Utilities Board Singapore (PUB) (2016) Managing the water distribution network with a Smart Water Grid, Smart Water International Journal for @qua - Smart ICT for Water 2016, 1:4

Ray PP (2016) A survey on Internet of Things architectures. Journal of King Saud University - Computer and Information Sciences (in press)

Ruan Y, Tang Y (2011) A water quality monitoring system based on wireless sensor network \& solar power supply. In: 2011 IEEE International Conference on Cyber Technology in Automation, Control, and Intelligent System, 20-23, Mar 2011

Sathish K, Sarojini M, Pandu R (2016) loT based real time monitoring of water quality. Int J Prof Eng Stud VII(5):174-179

Shuker Mahmoud, Mahmoud, Auday, Mohamad A. H. (2016) A Study of Efficient Power Consumption Wireless Communication Techniques/ Modules for Internet of Things (IoT) Applications Advances in Internet of Things 6:19-29

Texas instrument CC3200 Simple Link (2017) http://www.ti.com/product/CC3200. Accessed 24 July 2017

Theofanis PL, Christos CA, Christos GP, Marios MP (2014) A Low-Cost Sensor Network for Real-Time Monitoring and Contamination Detection in Drinking Water Distribution Systems. IEEE Ssensors J 14(8):2014

Thinagaran P, Nasir S, Leong CY (2015) Internet of Things (IoT) enabled water monitoring system. In: $4^{\text {th }}$ IEEE global conference on consumer electronics, 27-30 Oct. 2015

Thomas D, Wilkie E, Irvine J (2016) Comparison of Power Consumption of Wi-Fi Inbuilt Internet of Things Device with Bluetooth Low Energy. Intl J Comput Electrical Automation Control Inf Eng 10(10):1837-1840

Tomoaki K, Masashi M, Akihiro M, Akihiro M, Sang L (2016) A wireless sensor network platform for water quality monitoring. In: IEEE Sensors, Oct. 30-Nov. 32016

Ubidots (2017) loT platform | Internet of Things. https://ubidots.com/. Accessed 22 June 2017

Vijayakumar N, Ramya R (2015) The real time monitoring of water quality in loT environment. In: international conference on circuits, power and computing technologies, 19-20 March 2015

Vinod R, Sushama S (2016) Wireless acquisition system for water quality monitoring. In: Conference on advances in signal processing, 9-11 June 2016

Water Resource Information System of India (2017). http:/www.india-wris.nrsc.gov.in/wrpinfo/index.php?title=River_ Water_Quality_Monitoring. Accessed 2 May 2017

Wei D, Liu P, Lu B, GUO Z (2012) Water Quality Automatic Monitoring System Based on GPRS Data Communications. In: International conference on modern hydraulic engineering, 9-11 Mar 2012

Woon Choi Gye et al, (2016) SWMI: new paradigm of water resources management for SDGs, Smart Water International Journal for @qua - Smart ICT for Water 2016, 1:3

Xin W, Longquan M, Huizhong Y (2011) Online Water Monitoring System Based on ZigBee and GPRS. Adv Control Eng Inform Sci:2680-2684

Xiuli M, Xo H, Shuiyuan X, Qiong L, Qiong L, Chunhua T (2011) Continuous, online monitoring and analysis in large water distribution networks. In: International Conference on Data Engineering, 11-16. April 2011

Xiuna Z, Daoliang L, Dongxian H, Jianqin W, Daokun M, Feifei L (2010) A remote wireless system for water quality online monitoring in intensive fish culture. Computers Electronics Agriculture :S3-S9

\section{Submit your manuscript to a SpringerOpen ${ }^{\circ}$} journal and benefit from:

- Convenient online submission

- Rigorous peer review

- Open access: articles freely available online

- High visibility within the field

- Retaining the copyright to your article

Submit your next manuscript at $>$ springeropen.com 